\title{
Growth and yield assessment of lettuce (Lactuca sativa L.): an economic feasibility and performance evaluation of capillary wick irrigation system
}

\author{
Alvin John B. Felipe ${ }^{1 \star}$ \& Jeoffrey Lloyd R. Bareng ${ }^{1,2}$ \\ ${ }^{1}$ Water Research and Development Center, Isabela State University, Echague-3309, Philippines \\ ${ }^{2}$ College of Engineering, Isabela State University, Echague-3309, Philippines
}

^Email: alvinjohn.b.felipe@isu.edu.ph

OPEN ACCESS

\section{ARTICLE HISTORY}

Received: 29 August 2021

Accepted: 24 November 2021

Available online

Version 1.0:01 January 2022

Check for updates

Additional information

Peer review: Publisher thanks Sectional Editor and the other anonymous reviewers for their contribution to the peer review of this work.

Reprints \& permissions information is available at https://horizonepublishing.com/ journals/index.php/PST/open_access_policy

Publisher's Note: Horizon e-Publishing Group remains neutral with regard to jurisdictional claims in published maps and institutional affiliations.

Indexing: Plant Science Today, published by Horizon e-Publishing Group, is covered by Scopus, Web of Science, BIOSIS Previews, Clarivate Analytics, etc. See https:// horizonepublishing.com/journals/index.php/ PST/indexing_abstracting

Copyright: $\odot$ The Author(s). This is an openaccess article distributed under the terms of the Creative Commons Attribution License, which permits unrestricted use, distribution and reproduction in any medium, provided the original author and source are credited (https://creativecommons.org/licenses/ by/4.0/)

\section{CITE THIS ARTICLE}

Felipe A J B, Bareng J L R. Growth and yield assessment of lettuce (Lactuca sativa $\mathrm{L}$.): an economic feasibility and performance evaluation of capillary wick irrigation system. Plant Science Today. 2022;9(1):62-69. https:// doi.org/10.14719/pst.1460

\begin{abstract}
The study assessed the growth and yield of lettuce (Lactuca sativa L.) in order to evaluate the performance and economic feasibility of capillary wick irrigation system. Unlike any other capillary rise-based systems that uses the matric potential of the soil to dictate the amount of water to be drawn, this system aimed to continuously supply water imitating a full-time drip irrigation system but cheaper in terms of materials and operating cost. A 5 $\mathrm{mm}$-width, cotton fabric strip was used as a wick material based from the results of the preliminary testing to verify several literature claims. In order to determine number of wicks to optimally supply the water demand of lettuce, treatments namely, $T_{1}=1$ wick, $T_{2}=2$ wicks, $T_{3}=3$ wicks and a control treatment $T_{4}$ which uses manual irrigation method, were tested and compared against each other. Significant results were in terms of the volume of water applied, and the water use efficiency in which $\mathrm{T}_{1}$ showed a better performance among other treatments. However, it does not imply that $T_{1}$ had produced a supreme yield output. Instead, this can be attributed to the efficient application of irrigation water to an optimal level. This means that $\mathrm{T}_{1}$ or the use of 1 wick material minimizes irrigation water losses through evaporation and percolation. An economic analysis was performed and has resulted to a return on investment of $41.92 \%$ or $41.92 \%$ of the investment cost will be returned after three cropping, which is an attribute of the particular set-up cost of the study.
\end{abstract}

\section{Keywords \\ capillary action, water use efficiency, subirrigation, water optimization}

\section{Introduction}

Lettuce is one of the most significant leafy vegetables planted worldwide and consumed throughout the year (1). It is rich in vitamins and healthboosting contents that help to improve the bodily functions and immune system (2). Lettuce, on the other hand, is known to be one of the most sensitive to when it comes to water since adequate moisture is very vital on the plant's growth development, which is also the reason why it is optimum for lettuce to have a soil moisture content always close to field capacity (3).

Water is essential for plants as it serves as a big factor for growth and productivity (4). More so, it is considered to be the most heavily exploited resource that has led to various water scarcity problems around the world (5).

Due to the emerging effect of climate variability and natural phenom- 
ena, water scarcity has become a constraint in food production (6). Production is limited for people in areas without a reliable source of water for irrigation. Also, shortage in irrigation water affects the quality of the crops that would decrease its market value, which is equivalent to a loss of profit for the farmers.

Introducing water management protocols and conservation measures has become a field of practice. More people, expert or not, are now concerned to these kinds of ventures in order to sustain water and soil resources that apparently became the focus of environment related policies.

The increasing human population also contributes to water scarcity since it is directly proportional on the increasing water consumption and utilization (7). Water consumption over the years has grown to be more than double due to rapid increase in population (8).

Protected cultivations such as greenhouses has suggested to have positive economic return and very promising outputs in producing high value crops (9). The inside environment offers substantial advantages with lesser environmental impact. It can be an option for people who want to grow crops for their own consumption or even for those farmers who are eyeing for quality production. One of most efficient and suitable irrigation systems commercially available for greenhouses is drip irrigation system (11). However, most of the small-scale farmers lack capital to install drip irrigation systems and hence apply water manually using buckets and hosepipes, methods that are laborious and not efficient in water utilization (12). Also, using advance systems would require a need of frequent soil monitoring to ensure that the plants are getting sufficient supply of water from the soil and to monitor the irrigation to avoid over supply of water that will only result to a loss. Hi-tech instruments for such purpose such as moisture probes are expensive enough to be acquired by small farmers and the proper knowledge in using and maintaining such instruments is not of common interest.

To avoid this kind of predicament, researchers and engineers devote their time to heed, conceptualize, and develop different irrigation management systems.

Though it does not gather much popularity in the Philippines, a wick irrigation system is a proven alternative in minimizing water losses with the capacity to supply irrigation water and even nutritional requirement to crops (10). Capillary irrigation system, as a form of sub-irrigation system, uses capillary action to transport water from the source to the root zone of the crop (13). It takes advantage on the capillary action of the medium to transport water to the soil. Subsurface micro-irrigation has some potential advantages over surface irrigation. These include reduction of soil evaporation, surface runoff, and deep percolation; greater savings of water, nutrients, and labor; and improved crop quality. It also minimizes the contact of irrigation water to the plant that could cause damage due to present pathogenic microorganisms (14).

Some types of capillary irrigation system utilize capillary rise like wicking bed systems where water rises
Table 1. Capillary Rise Extent

\begin{tabular}{cc}
\hline Sample & Capillary Rise \\
\hline 1 & 8 \\
2 & 8 \\
3 & 8 \\
4 & 7 \\
F-value @ 5\% & $0.70^{\text {ns }}$ \\
\hline
\end{tabular}

passing thru the soil due to a suction force cause by capillary action (13) which makes the soil condition as affected by the plant's transpiration rate and equivalent evapotranspiration, the driving force in dictating the amount of water to be transported. As the water depletes from the soil, there would be a greater matric potential that will trigger adhesive forces to become greater (15) which will cause the movement of water towards the soil where the wick or transporting medium is connected. This study, however uses different approach where the operation of the system is patterned out of the operation of a drip irrigation system

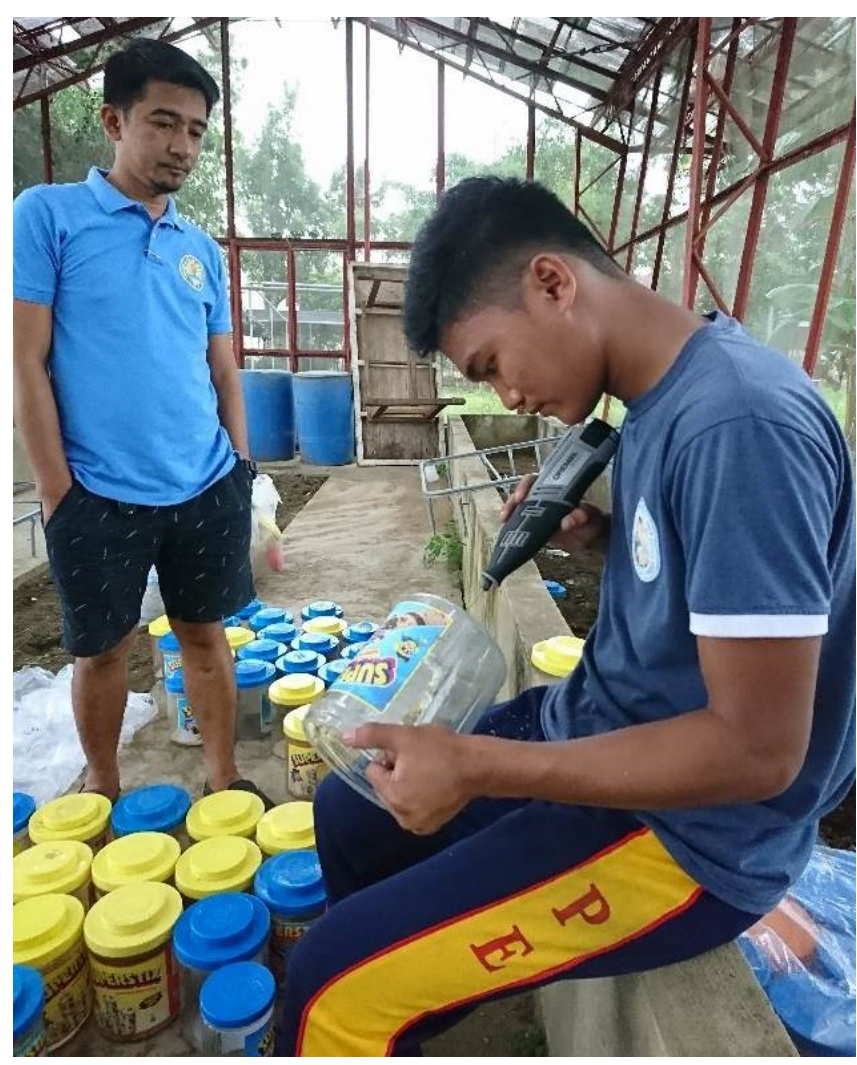

Fig. 1. The researchers drilling percolation holes on the plant-soil containers.

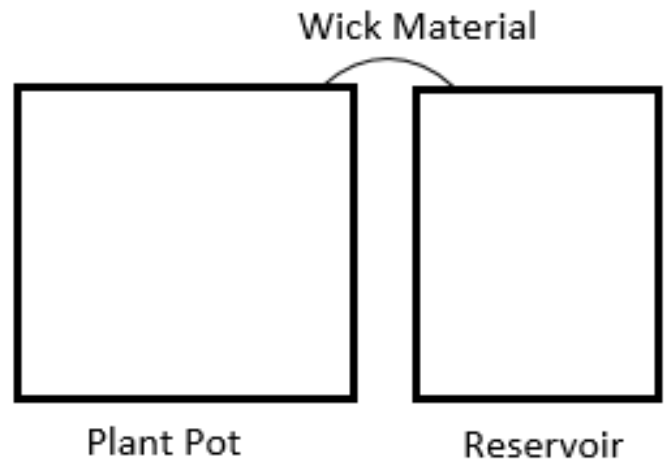

Fig. 2. Configuration of the wick system. 
by having the transport medium (wick) serve the purpose of an emitter in order to regulate the transport of water imitating a full-time drip irrigation system. It was done to improve water application rate since it is a vital factor that influences soil moisture in a drip irrigation system which this system imitates (16).

Capillary irrigation system is useful in minimizing the work needed in watering the plants in a daily basis by simply supplying the amount of water for plant consumption for



Fig. 3. The actual set-up of the system.

a duration of time where labor will not be present. The use of capillary wicks in irrigating plants is proven to produce positive results when being applied in nurseries efficient irrigation management (17).

In this system, the wick will transport continuously until it consumes all the water from the source. The decline of water from the water reservoir will be limited to a common level to indicate that a refill is needed. In farming applications, the interval of refilling may vary from the size of the container serving as the source of water. Hence, it minimizes irrigation efforts by giving opportunity to the farmers to set amount of water to be stored for consumption thereby dictating the irrigation interval and consequently, reducing excess labor. All this being done without a supplementary aid of soil moistures and sensors.

The purpose of this study is to evaluate the performance of the wick irrigation system that aims to reduce the effort on the part of the farmers and the professionals who want to engage in growing lettuce and similar crops by contributing to a better time, labor, and cost management. The determination of the economic feasibility of the system is also in consideration to address the financial aspect attributed in the system and to enhance its potential as an alternative form of water management system (18).

\section{Materials and Methods}

\section{Time and place of the study}

This study was conducted at the Cagayan Valley Aquatic and Agricultural Resource Research Development (CVAARRD) Experiment and Demonstration Area, Isabela
State University, Echague, Philippines. The duration of the study includes the time covered from pre-testing the wick materials and final conduct of the study which was conducted on the last quarter of February up to the last week of March 2020 where the length of crop after transplanting up to harvest is about 45 days where the temperature range was $20.6^{\circ} \mathrm{C}$ to $31.8^{\circ} \mathrm{C}$, relative humidity ranges from $47.3 \%$ $68 \%$ and the average radiation of $16.1 \mathrm{MJ} / \mathrm{m}^{2} /$ day was recorded.

One of the major factors in identifying and selecting the experimental site is the existence of glasshouse facility which is essential in providing a homogenous environment to the plants. And, such experimental area suited for the study is located at the CVAARRD Complex, ISU, Echague.

\section{Preparation and testing of wicking material}

According to one report (19), cotton twine from mop-head (5 $\mathrm{mm} \mathrm{m}$ in diameter) was a good wick material. However, the $\overline{V T}$ results of the preliminary test of the locally purchased mop-heads show that neither of the mop heads has the capability to transport water.

Since one of the objectives of the study is to use cheap and commercially available materials, an experiment was conducted to identify which of the commercially available cotton materials is capable of transporting water and to what extent it could possibly reach. The experiment also substantial in assessing the optimal length of the wick material so that the fabric material from where the wicks are to be made will be fully utilized. The methods are as follows:

1). Out of the all the possible cotton materials, a $100 \%$ cotton blanket woven fabric was selected and put under testing out of 4 cotton materials acquired at the local market which are the following: cotton T-shirt, cotton towel, cotton pants.

2). Four strips of $5 \mathrm{~mm}$ in width cotton fabrics were

$\mathrm{ROI}=\frac{P}{I C} \times 100,(26)$

hanged on the side of a container, submerging equal lengths of end parts to the same amount of water (0.75 l).

3). The maximum observed capillary rise of the wicks were observed and measured were shown in (Table 1).

\section{Preparation of experimental units}

$\mathrm{BES}=\frac{F C}{S P-V C},(27)$.

Lettuce (L. sativa L.) of the family Asteraceae, grows best in loose soil proper drainage quality or the ease that the water can pass through the soil (20). In the preparation of soil media, the researchers used a ratio of 2:1 mixture of carbonized rice hull and clay soil respectively, since it is readily available on the site and has a good drainage attribute. A transparent plastic container or pot was used to harbor the soil media. The container has a dimension of approximately $10 \mathrm{~cm}$ in diameter and a depth of $17 \mathrm{~cm} \mathrm{(21).} \mathrm{Each} \mathrm{plastic}$ pot was drilled on the bottom for percolation purposes (Fig. 1). Each pot contains one seedling with corresponding wick material installed based on the designated treatment. Each 
pot assembly has an individual water reservoir (Fig. 2).

\section{Installation of wicking material}

The wicks were equally wetted prior to installation to hasten the transport of water to the experimental plants and the level of soil moisture on every plant sample was set to be approximately the same at $15 \%$.

Capillary irrigation was long been evaluated in supplying water for container gardening (22). The system configuration is shown in Fig. 3. The plant pot and the reservoir per system was installed beside each other (Fig. 2). The ex-

Table 2. Average Number of Leaves

\begin{tabular}{cc}
\hline Treatment & Number of Leaves \\
\hline 1 & 8 \\
2 & 8 \\
3 & 8 \\
4 & 7 \\
F-value @ 5\% & $0.70^{\text {ns }}$ \\
\hline
\end{tabular}

posed part of the wick after installation into the experimental pot was covered with a plastic tube or hose to prevent evaporation and the end tip of the wick was connected

Table 3. Length of Leaves $(\mathrm{cm})$

\begin{tabular}{cccc}
\hline Treatment & \multicolumn{3}{c}{ Average Length of Leaves } \\
\hline & 1 WAT & 2 WAT & 3 WAT \\
2 & 6.23 & 10.16 & 12.94 \\
3 & 6.81 & 11.05 & 12.51 \\
4 & 6.04 & 10.33 & 12.64 \\
F-value @ 5\% & 6.02 & 10.57 & 13.14 \\
\hline
\end{tabular}

to the covered container or water reservoir which was individually installed per plant. The amount of water consumed by each experimental plant was monitored through checking of the actual depth of water in the designated water reservoir.

\section{Crop maintenance and soil moisture monitoring}

The lettuce seedlings were acquired from a nursery four weeks after seeding to ensure that they were properly taken care of from seeding before transplanting. The plant agronomic parameters were closely observed started from 1 Week After Transplanting (WAT) up to its matured and harvestable state after 3 WAT. Five sample plants were randomly considered per treatment in measuring the length of the experimental crop which were taken through the use of a ruler.

Table 4. Width of Leaves $(\mathrm{cm})$

\begin{tabular}{cccc}
\hline Treatment & \multicolumn{3}{c}{ Average Width of Leaves } \\
\hline & 1 WAT & 2 WAT & 3 WAT \\
2 & 3.90 & 6.81 & 8.96 \\
3 & 2.83 & 4.99 & 7.11 \\
4 & 3.23 & 5.17 & 6.84 \\
F-value @ 5\% & 2.97 & 5.24 & 7.43 \\
\hline
\end{tabular}

The researchers added a measured amount of urea fertilizer during the 2 WAT as control since loose leaf varieties need only one side-dressing of 46-0-0 fertilizer at $5 \mathrm{~g} /$ plant at fifteen days after transplanting (23).

The crops were taken care by carefully removing the weeds minimally growing inside the plant containers and by spraying a considerable amount of insecticide to avoid possible insect-borne diseases that may affect the performance of the crops.

The growth of the crops was observed rigorously. Each leaf growth was recorded where the corresponding length and width were taken until the leaf ceases to grow or wilts.

The plant yield was assessed after about 75 days after sowing by getting the average weight of the five harvested sample plants per treatment. All possible dry matters were gathered at each plant to be honestly reflected in the water use efficiency assessment.

The soil moisture content of each pot was monitored everyday using a digital moisture probe to monitor the amount of moisture present in the soil and to analyse if

Table 5. Total Yield (g).

\begin{tabular}{cc}
\hline Treatment & Total Yield \\
\hline 1 & \\
2 & 15.87 \\
3 & 15.53 \\
4 & 20.8 \\
F-value @ 5\% & 14.3 \\
\end{tabular}

there is a significant variation among treatments in terms of soil moisture being retained in the soil.

The total volume of water supplied into the water reservoir throughout the duration of the study was recorded. The refill was made when the water decline reaches the set limit.

The water use efficiency of the experimental plants was computed through the application of the formula:

WUE $=X 100,(24)$

where WUE is water use efficiency, $m$ is the total weight of Table 6. Volume of Water Applied (li)

\begin{tabular}{cc}
\hline Treatment & Volume of Water \\
\hline 1 & 0.68 \\
2 & 2.35 \\
3 & 3.56 \\
4 & 1 \\
HSD @ 5\% & $0.2457^{\text {*highlysignificant }}$ \\
\hline
\end{tabular}

the plant at harvest and $V T$ is the total volume of water applied. It represents the relationship of yield obtained to the amount of water applied (25).

\section{Statistical analysis}

All data collected were subjected to Analysis of Variance 
(ANOVA) for Completely Randomized Design (CRD) at 5\% and $1 \%$ level of significance. Comparison of treatments means were performed for ANOVA with significant results using the protected Fisher's Least Significant Difference (Tukey's HSD-Honest Significant Difference) test at significant level 5\%.

In order to assess the economic feasibility of the system, the following parameters were considered in order to analyse the economic aspects of the system:

\section{Return on investment}

The return on investment was computed through the use of the formula,

Table 7. Average Moisture Content (\% wet basis)

\begin{tabular}{cc}
\hline Treatment & Moisture Content \\
\hline 1 & 19.96 \\
2 & 17.90 \\
3 & 18.89 \\
4 & 18.35 \\
F-value @ 5\% & $0.20^{\mathrm{ns}}$ \\
\hline
\end{tabular}

where $\mathrm{ROI}$ is the return of investment, $P$ is the profit, and $I C$ is the investment capital.

\section{Break even analysis}

The break-even point analysis was computed thru the use of equation,

where BES is the break-even sales or the amount of lettuce to be sold in order to cover to total investment cost, $F C$ is the fixed cost, $S P$ is the selling price, and $V C$ is the variable cost.

\section{Results and Discussion}

\section{Plant agronomic parameters}

\section{Number of leaves}

The number of leaves was observed to monitor the response of the plant samples to the treatment. With an average of 8 leaves per plant, the plant samples of each treatment were observed to have an almost the same number of

Table 8. Water Use Efficiency (g/li)

\begin{tabular}{cc}
\hline Treatment & Water Use Efficiency \\
\hline 1 & 23.41 \\
2 & 6.97 \\
3 & 6.24 \\
4 & 13.47 \\
HSD @ 5\% & 9.0733 *highly significant \\
\hline
\end{tabular}

leaves against each other. However, the Analysis of Variance (ANOVA) for the number of leaves as shown in (Table 2) has an insignificant result (5\% level of significance) which strongly suggest that the number of leaves of plant was not affected by the treatments. The results were in accordance with the study conducted earlier $(28,29)$ which observed that growth and in like manner, number of leaves is a developmental character that is mainly temperature dependent.

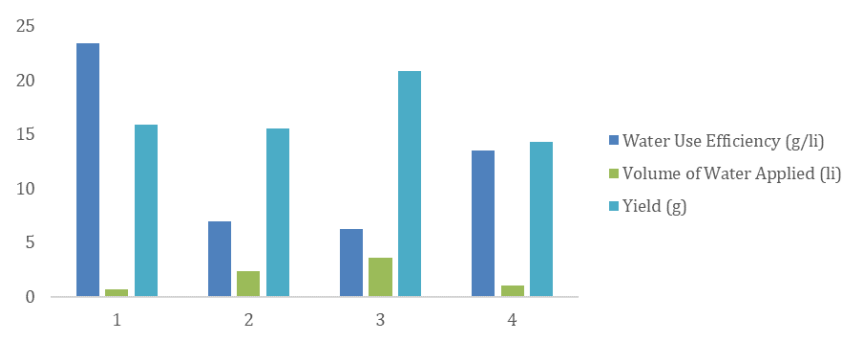

Fig. 4. Water use efficiency comparison between treatments

\section{Length and width of leaves}

The length of leaves one week after transplanting (WAT), as shown in (Table 3) indicated that among the treatment means, treatment 2 produced the longest leaf length average of $6.81 \mathrm{~cm}$ on compared to $6.23 \mathrm{~cm}, 6.04 \mathrm{~cm}$ and 6.02 $\mathrm{cm}$ for treatments 1,3 and 4 respectively. For 2 WAT the highest leaf length registered to treatment 2 with an average of $11.05 \mathrm{~cm}$ as compared to treatments 1,3 and 4 with respective average values of $10.16 \mathrm{~cm}, 10.33 \mathrm{~cm}$ and 10.57 $\mathrm{cm}$. During 3 WAT, treatment 4 attained the highest mean length of $13.14 \mathrm{~cm}$ which is followed by treatment 1,3 and 2 with average values of $12.94 \mathrm{~cm}, 12.64 \mathrm{~cm}$ and $12.64 \mathrm{~cm}$ respectively. The observed differences in leaf length of the different treatments, however, revealed an insignificant result at $5 \%$ level of significance for each respective week throughout the conduct of the experiment.

In terms of the width of leaves, the data collected is

Table 9. Return on Investment

Investment Capital $=\ngtr 3,805$

Profit after 3 cropping $=5,400$

ROI after 3 cropping $=41.92 \%$

Table 10. Break-even Analysis

Fixed Cost $=\ngtr 3,805$

Selling Price $=60 /$ bundle

Variable Cost $=6$ (assume 10\%)

Break-even Sales $=71$ bundles per cropping

shown in (Table 4). For 1 WAT, treatment 1 has the highest average value of $3.90 \mathrm{~cm}$ followed by treatment 3,4 and 2 with the corresponding values of $3.23 \mathrm{~cm}, 2.97 \mathrm{~cm}$ and 2.82 $\mathrm{cm}$ respectively. For 2 WAT treatments 1 was the highest having an average leaf width of $6.81 \mathrm{~cm}$ followed by treatment 4,3 as 2 having an average value of $5.24 \mathrm{~cm}, 5.17 \mathrm{~cm}$ and $4.99 \mathrm{~cm}$ respectively. On 3 WAT, the data showed that treatment 1 acquired the highest leaf width with an average of $8.95 \mathrm{~cm}$ compared to $7.11 \mathrm{~cm}, 6.84 \mathrm{~cm}$ and $7.43 \mathrm{~cm}$ for treatments 2, 3 and 4 respectively.

Although treatment 1 has been consistently leading in terms of leaf width throughout the conduct of the experiment, statistical analysis revealed that treatment means are not significantly different from one another. Results thereby suggest that performance of treatment 1 and other treatments in terms of leaf width were comparable.

Yield

The yield is an important parameter to assess the water use 
efficiency of the system. The total yield of the system per treatment was considered for the analysis (Table 5). Statistical analysis revealed, however, that the yield for the different treatments were statistically comparable and insignificant.

\section{Volume of water applied}

One of the objectives of this study the assessment of the efficiency of the system in terms of the volume of water that was consumed by plant to measure water productivity (30). To closely monitor the amount of water consumed by each plant, the water reservoir of each plant is being refilled when the decline on water level reached the designated limit wherein the wick material can transport water. As shown in (Table 6), treatment 3 consumed the highest averaged amount of water among other treatments consuming about 3.56 I of water while treatment 1 approximately consumed the least amount of water at $0.68 \mathrm{l}$.

Statistical analysis for the volume of water applied resulted to a highly significant outcome. Further analysis using the Tukey HSD as a post hoc method in comparing the treatment means suggests that treatment 1 has transported the least amount of water which makes it the best treatment in terms of water efficiency. Treatment 4 sits behind treatment 1 and the result shows that treatment 2 and 3 transported to their respective plants the most amount of water which is not suitable in terms of water optimization.

\section{Moisture Content}

The ability of the wick to continuously transfer water was assessed by getting the moisture content of soil in each experimental pot every day. The soil moisture content is a great indicator of the wick's capacity in transporting water. The moisture trend per day all throughout the study, shows that the difference of moisture readings varies depending on the treatment. However, further analysis of data (Table 7) revealed that neither of the treatments affects the real variability of the moisture content.

The above-mentioned statement implies that soil moisture content is of maximum level regardless of the number of the wick installed. This further imply the excessive volume of water applied for treatments 4, 2 and 3 were just lost through evaporation and percolation.

\section{Water use efficiency}

The Water Use Efficiency (WUE) is a factor of the total volume or amount of water consumed by the plant and the total economic plant yield or the ratio of water utilized by the plant to the moisture lost by the plant during transpiration (31).

Treatment 1 attained the highest total WUE of 70.22 g liter ${ }^{-1}$ while treatment 3 was considered as the least at $18.73 \mathrm{~g} / \mathrm{l}$. Analysis of Variance for WUE suggests that the treatments have a highly significant effect. Since the ANOVA result is significant, Tukey HSD has been used to compare the treatment means and the analysis shows that treatment 1 attains the highest value which makes it the treatment to consider in terms of WUE (Table 8).

The results, however, does not imply that treatment 1 gave a supreme yield output instead, this may be attribut- ed to the efficient application of irrigation water to an optimal level. This means that treatment 1 minimizes irrigation water losses through evaporation and percolation. The comparison in terms of WUE between treatments is shown in (Fig. 4).

\section{Economic Analysis}

Considering the area, the relative cost utilized for the experiment, and the total yield, the economic analysis was done in order to assess the potential of this kind of wick irrigation system in terms of water-efficient production. The average yield used in the analysis was the average yield of the system since there is no significant difference in terms of yield among treatments as supported by the results of the study. The economic analysis of the system shows that the Return on Investment of $41.92 \%$ will be attained after three (3) cropping (Table 9) with a corresponding yield of at least 30 bundles each cropping to break-even (Table 10). Since the lettuce seedlings can be readily purchased at nurseries or be propagated in-house, sustainable production can be met. In this particular study, the lettuce was ready for harvest after 45 days which in economical perspective, it would take 135 days or less than 5 months to achieve more than $100 \%$ return on investment after three cropping. .

\section{Conclusion}

The analysis of all the data collected during the study has resulted and confirmed that Capillary Irrigation System can be used effectively in the production of lettuce.

Based on the results of the study, it was observed that the optimal length of the wick material for capillary system suitable to transporting moisture from the reservoir into the soil or growing media was found to be $21 \mathrm{~cm}$. It means that the length of the weak material should not exceed more than $21 \mathrm{~cm}$ when $100 \%$ cotton fabric is to be used as a wicking material.

The growth parameters were comparable to each other another, except for Volume of Water Applied and Water Use Efficiency, wherein treatment 1 performed best by efficiently and optimally conveying irrigation water into the growing media compared to other treatments.

The system's performance in terms of its economic viability was found to be feasible with an $\mathrm{ROI}$ of $41.92 \% \mathrm{ROI}$ and break-even sales of 71 bundles for a three-cropping cycle. The economic analysis is also very promising as it reflects high cropping intensity per year since it only takes 45 days per one cropping using transplanted seedlings readily available from the market or grown in-house.

The study shows that the use of wick material is not substantial in terms of plant growth parameters as compared to manual irrigation (treatment 4). However, the results of the study have proven that in terms of water management, capillary irrigation can significantly reduce water that takes place during irrigation water application.

It is also adoptable to anyone who wants to engage into farming since the principle is very easy to follow. The components used in the conduct of the study are can be 
replaced by recycled ones in the adaptation process to lower the investment cost thereby increasing the ROI of the system. In addition, the system can also eliminate time related and labour constraints since there would be a lesser effort needed with regards to timely irrigation application 7 and monitoring.

Finally, the study shows that capillary wick irrigation system, at one of its simplest form, can really contribute in the emerging problems and issues that are now facing agricultural water development in the such as water scarcity, how to increase the productivity of existing water resources, and how to respond to climate change.

\section{Acknowledgements}

The authors would like to appreciate and acknowledge the Isabela State University Vice President for Research and Development, Extension and Training, Prof. Orlando F. Balderama, PhD for his support and recognition on the potential of the study, and in giving insights and valuable advices; Engr. Melanie Aquino, M.Sci for her extended assistance by sharing time to improve the technical aspects of the study.

\section{Authors contributions}

AJBF proposed the concept of the study. He prepared the study area including the materials and collected the data from the plant samples. JLRB modifies the design of the study as proposed by AJBF and has contributed mainly by providing the inputs significant for further improvement and for supervising the conduct of the study. Both the authors contributed for literature survey, analysis of data and provided significant contribution in the formulation of the paper.

\section{Compliance with ethical standards}

Conflict of interest: Authors do not have any conflict of interests to declare.

Ethical issues: None.

\section{References}

1. Chen Z, Han Y, Ning K, Luo C, Sheng W, Wang S et al. Assessing the performance of different irrigation systems on lettuce (Lactuca sativa L.) in the greenhouse. PLOS ONE. 2019;14(2). https://doi.org/10.1371/journal.pone.0209329

2. Kim MJ, Moon Y, Tou JC, Mou B, Waterland NL. Nutritional value, bioactive compounds and health benefits of lettuce (Lactuca sativa L.). Journal of Food Composition and Analysis. 2016;49:1934. https://doi.org/10.1016/j.jfca.2016.03.004

3. Pessarakli M. Handbook of plant and crop physiology. Boca Raton, FL: CRC Press; 2021.

4. Karam F, Mounzer O, Sarkis F, Lahoud R. Yield and nitrogen recovery of lettuce under different irrigation regimes. Journal of Applied Horticulture. 2002;04(02):70-76. https:// doi.org/10.37855/jah.2002.v04i02.21

5. Ali H. In: Practices of irrigation and amp; on-farm water management: vol. 2. New York, New York: Springer; 2014. p. v-vi. https:// doi.org/10.1007/978-1-4419-7637-6

6. Misra AK. Climate change and challenges of water and food security. International Journal of Sustainable Built Environment. 2014;3(1):153-65. https://doi.org/10.1016/j.ijsbe.2014.04.006

7. Boretti A, Rosa L. Reassessing the projections of the World Water Development Report [Internet]. Nature News. Nature Publishing Group; 2019 [cited 2021Apr21]. Available from: https:// www.nature.com/articles/s41545-019-0039-9

8. Kuntz LB. Wick Irrigation Systems for Subsistence Farming. Cambridge: Massachusetts Institute of Technology, 2013.

9. Saravaiya S, Kumar S, Patel N. Protected Cultivation: Future Technology for Vegetable Crops [Internet]. [cited 2021Apr19]. Available from: https://www.researchgate.net/ publica-

tion/333508562_Protected_Cultivation_Future_Technology_for_ Vegetable_Crops

10. Elaydi H. An Automated Irrigation System for Greenhouses. American Journal of Electrical and Electronic Engineering. 2017;5 (2):48-57. https://doi.org/10.12691/ajeee-5-2-3

11. Wesonga J, Wainaina C, Ombwara FK, Masinde P, Home P. [PDF] Wick Material and Media for Capillary Wick Based Irrigation System in Kenya: Semantic Scholar [Internet]. [PDF] Wick Material and Media for Capillary Wick Based Irrigation System in Kenya | Semantic Scholar. 1970 [cited 2021Apr19]. Available from: https://www.semanticscholar.org/paper/Wick-Material-andMedia-for-Capillary-Wick-Based-in-WesongaWainaina/871d3267ade7bdaff20717b2cc6f372d9a070f72

12. Ferrarezi RS, Testezlaf R. Performance of wick irrigation system using self-compensating troughs with substrates for lettuce production. Journal of Plant Nutrition. 2014;39(1):147-61. https:// doi.org/10.1080/01904167.2014.983127

13. Semananda N, Ward J, Myers B. A semi-systematic review of capillary irrigation: The benefits, limitations and opportunities. Horticulturae. 2018;4(3):23. https://doi.org/10.3390/ horticulturae4030023

14. Hong CX. Plant pathogens in irrigation water: Challenges and opportunities. Critical Reviews in Plant Sciences. 2005;24(3):189208. https://doi.org/10.1080/07352680591005838

15. Whalley WR, Ober ES, Jenkins M. Measurement of the matric potential of soil water in the rhizosphere. Journal of Experimental Botany. 2013;64(13):3951-63. https://doi.org/10.1093/ jxb/ert044

16. Assouline $\mathrm{S}$. The effects of microdrip and conventional drip irrigation on water distribution and uptake. Soil Science Society of America Journal. 2002;66(5):1630-36. https://doi.org/10.2136/ sssaj2002.1630

17. Nalliah V, Sri Ranjan R. Evaluation of a Capillary-Irrigation System for Better Yield and Quality of Hot Pepper (Capsicum annuum). Applied Engineering in Agriculture. 2010;26(5):807-16. https://doi.org/10.13031/2013.34941

18. Mukherjee M, Roy S. Feasibility Studies and Important Aspect of Project Management. International Journal of Advanced Engineering and management. 2017;2(4):98. https:// doi.org/10.24999/ijoaem/02040025

19. Orge FR, Sawey AD. Field performance of the capillary wick irrigation (capillarigation) system for rice-based crops. International Journal of GEOMATE. 2019;17(61). https:// doi.org/10.21660/2019.61.4636

20. Growing Lettuce: A guide to planting and amp; Harvesting Lettuce [Internet]. Gilmour. 2020 [cited 2021Apr19]. Available from: https://gilmour.com/growing-lettuce

21. Cumberledge K. Ultimate guide to growing lettuce in containers [Internet]. Happy DIY Home. 2020 [cited 2021Apr19]. Available from: https://happydiyhome.com/growing-lettuce-in- 
containers/

22. Semananda N, Ward J, Myers B. A Semi-Systematic Review of Capillary Irrigation: The Benefits, Limitations and Opportunities. Horticulturae. 2018;4(3):23. https://doi.org/10.3390/ horticulturae 4030023

23. Lettuce Production Guide. Tuguegarao City, Philippines: Department of Agriculture Field Office No. 02, High Value Crops Program.; 2017.

24. Howell T. Irrigation. Encyclopedia of Water Science, $2^{\text {nd }}$ edition (Print Version). 2007;45:640-45. https://doi.org/10.1201/ noe0849396274.ch151

25. WATER: Calculating water use indices to benchmark water use efficiency [Internet]. CottonInfo. [cited 2021Apr19]. Available from: https://www.cottoninfo.com.au/publications/watercalculating-water-use-indices-benchmark-water-use-efficiency/

26. Zamfir M, Manea MD, Ionescu L. Return on investment - Indicator for measuring the profitability of invested capital. Valahian Journal of Economic Studies. 2016;7(2):79-86. https:// doi.org/10.1515/vjes-2016-0010

27. Break Even Point Formula: Steps to Calculate BEP (Examples) [Internet]. WallStreetMojo. 2021 [cited 2021Apr19]. Available from: https://www.wallstreetmojo.com/break-even-formula/
28. Marcelis-van Acker CAM. Effect of temperature on development and growth potential of axillary buds in roses. Scientia Horticulturae. 1995;63(3-4):241-50. https://doi.org/10.1016/0304-4238 (95)00802-z

29. Steininger J, Pasian CC, Lieth JH. Extension of a thermal unit model to represent nonlinearities in temperature response of miniature rose development. Journal of the American Society for Horticultural Science. 2002;127(3):349-54. https:// doi.org/10.21273/jashs.127.3.349

30. Hamdy A. (PDF) Water use efficiency in irrigated agriculture: an ... [Internet]. [cited 2021Apr19]. Available from: https:// www.researchgate.net/

publica-

tion/239533424_Water_use_efficiency_in_irrigated_agriculture_ an_analytical_review

31. Zahoor SA, Ahmad S, Ahmad A, Wajid A, Khaliq T, Mubeen M et al. Improving water use efficiency in agronomic crop production. Agronomic Crops. 2019;:13-29. https://doi.org/10.1007/978-98132-9783-8_2 